\title{
Two New Triterpenoid Glycosides from the Leaves of Schefflera octophylla
}

\author{
Junichi KITAJIMA* and Yasuko TANAKA \\ Showa College of Pharmaceutical Sciences, 5-1-8 Tsurumaki, Setagaya-ku, Tokyo 154, Japan. Received January 21, 1989
}

Two new triterpenoid glycosides were isolated from the leaf blades and the petioles of Schefflera octophylla (Araliaceae). Their structures were characterized as $3 \alpha$-hydroxylup-20(29)-ene-23,28-dioic acid 28-O- $\alpha$-Lrhamnopyranosyl- $(1 \rightarrow 4)$ - $O$ - $\beta$-D-glucopyranosyl-( $1 \rightarrow 6)-\beta$-D-glucopyranoside and 3 -epi-betulinic acid 3-O- $\beta$-Dglucopyranoside on the basis of spectral and chemical investigations. NMR

Keywords Schefflera octophylla; Araliaceae; lupane-type triterpenoid 28-O-glycoside; lupane-type triterpenoid 3- $O$-glycoside;

Schefflera octophylla (Araliaceae; fukanoki in Japanese) has been used in Chinese and Vietnamese folk medicine as an anti-pyretic, anti-inflammatory, analgesic, tonic, and as a drug for the treatment of liver disease. From the leaves of this plant, Adam et al. reported the isolation of two lupanetype triterpenoids, and their structures were shown to be $3 \alpha$-hydroxylup-20(29)-ene-23,28-dioic acid ${ }^{1)}$ and $3 \alpha, 11 \alpha$ dihydroxylup-20(29)-ene-23,28-dioic acid. ${ }^{2)}$

The present study was done to isolate and characterize a new lupane-type triterpenoid 28-O-glycoside from fresh leaf blades of this plant, and a new lupane-type 3-O-glycoside from the fresh petioles.

The $\mathrm{MeOH}$ extract of fresh leaf blades was successively heated under reflux with hexane, ether, acetone and $\mathrm{MeOH}$, and the extract of the $\mathrm{MeOH}$ soluble fraction was subjected to a combination of column chromatographies on Amberlite XAD-II, silica gel, Sephadex LH-20 and a Lobar RP-8 column to give glycoside I.

Glycoside I (1) was positive for the LiebermannBurchard reaction and showed distinctive absorptions in its infrared (IR) spectrum due to hydroxyl $\left(3400 \mathrm{~cm}^{-1}\right)$, carboxyl $\left(1720,1705 \mathrm{~cm}^{-1}\right)$ and exo-methylene $(1640,880$ $\left.\mathrm{cm}^{-1}\right)$ groups. The proton and carbon-13 nuclear magnetic resonance $\left({ }^{1} \mathrm{H}\right.$ - and $\left.{ }^{13} \mathrm{C}-\mathrm{NMR}\right)$ spectral data for 1 showed the presence of five tertiary methyls, one secondary methyl, two olefinic protons, three anomeric protons $(\delta 4.81$, doublet, $J=8 \mathrm{~Hz} ; \delta 5.55$, singlet; $\delta 6.12$, doublet, $J=7 \mathrm{~Hz}$ in the ${ }^{1} \mathrm{H}-\mathrm{NMR}$ spectrum) and three anomeric carbons ( $\delta 95.3$, 102.6 and 105.0 in the ${ }^{13}$ C-NMR spectrum).

Acid hydrolysis of 1 gave an aglycone identical with $3 \alpha-$ hydroxylup-20(29)-ene-23,28-dioic acid (2), which was isolated from the ether soluble fraction of the $\mathrm{MeOH}$ extract of the leaf blade, together with D-glucose and L-rhamnose as sugar components.

On partial hydrolysis under mild conditions using $0.3 \mathrm{~N}$ methanolic- $\mathrm{H}_{2} \mathrm{SO}_{4}, 1$ afforded 2, methyl rhamnoside, methyl glucoside and methyl gentiobioside. From these results, 1 was considered to be a trisaccharide of 2 , with one molecule of rhamnose and two molecules of glucose. Alkaline hydrolysis of $\mathbf{1}$ also gave $\mathbf{2}$, indicating that the sugar residue was linked to the aglycone by an ester bond.

The peracetate (3) of 1 was obtained by the usual method $\left(\mathrm{Ac}_{2} \mathrm{O}\right.$-pyridine at room temperature for $\left.12 \mathrm{~h}\right)$, and 3 monomethylate (4) was produced by methylation with ethereal diazomethane in $\mathrm{MeOH}$. Thus, 1 was suggested to be a monodesmoside with the sugar residue linked to C-23 or C-28.

The location of the sugar residue of 1 was clarified by consideration of the electron impact mass spectral (EI-MS) fragmentation pattern and the ${ }^{13} \mathrm{C}-\mathrm{NMR}$ spectrum of 4 compared with those of derivatives of 2 : the $23,28-\mathrm{di}-$ methylate (2a), the 3-acetoxy-23,28-dimethylate (2b) and the 3-oxo-23,28-dimethylate (2c).

The EI-MS of 3 and 4 each exhibited two peaks due to terminal tri- $O$-acetylrhamnose $(m / z \quad 273)$ and tri- $O$-acetylrhamnosyl tetra- $O$-acetylglucose $(m / z 561)$, but there was no peak due to terminal tetra- $O$-acetylglucose $(\mathrm{m} / \mathrm{z}$ $331) .^{3)}$ It was suggested that the terminal sugar was rhamnose and that the sugar chain was linear. The other fragments of 4 were mainly characterized by bond cleavages of ring C, as shown in Fig. 1, ${ }^{1)}$ and these fragments implied an assignment of the sugar residue to C-28.

Further confirmation was obtained by comparison of the ${ }^{13} \mathrm{C}-\mathrm{NMR}$ signals due to the aglycone part of 4 with those of $\mathbf{2}$ and some derivatives $(\mathbf{2 a}, \mathbf{2 b}$ and $\mathbf{2 c})$. The carbon signals of the 28-carbomethoxy group of $\mathbf{2 b}$ were assigned to $\delta 176.5$ and 51.2 by comparison with $2 \mathrm{a}$ and $2 \mathrm{c}$ and thus the signals due to the 23-carbomethoxy group were assigned to $\delta 175.3$ and 50.3 (Table I).

From these data, the sugar residue was concluded to be attached to C-28 of 2 , and the sugar moiety was assigned as glucose $\stackrel{1 \rightarrow 6}{\text { glucose-rhamnose. }}$

The structure of the sugar moiety of 1 was elucidated by ${ }^{13} \mathrm{C}$-NMR studies. In ${ }^{13} \mathrm{C}$-NMR spectroscopy of oligosaccharides, it has been reported that the carbons of the terminal monosaccharide units have much longer spinlattice relaxation times $\left(T_{1}\right)$ than those of the inner units, and by means of the partially refluxed Fourier transform (PRFT) method, the carbon resonances due to individual monosaccharide units can be distinguished from one other. ${ }^{4)}$

Inspection of the PRFT spectrum of $1^{5)}$ as well as a comparison of its signals with those of $\beta$-gentiobiopyranoside, $2-\alpha$-rhamnosyl and $4-\alpha$-rhamnosyl $\beta$-glucopyranosides, $\beta$-glucopyranoside and $\alpha$-rhamnopyranoside, ${ }^{5,6)}$ disclosed that the terminal monosaccharide unit (longer $T_{1}$ value) can be assigned as $\alpha$-rhamnopyranoside. ${ }^{6 a)}$ The set of signals with medium $T_{1}$ values was consistent with 4- $\alpha$ rhamnosyl $\beta$-glucopyranoside, ${ }^{6 b)}$ and signals with shorter $T_{1}$ values were assigned to 6 - $\beta$-glucosyl $\beta$-glucopyranoside. The anomeric carbon signals of 6 - $\beta$-glucosyl $\beta$-glucopyranoside $(\delta 95.3)$ showed that this glucose was linked to the aglycone by an ester bond. ${ }^{7)}$

From these data, it was concluded that the sugar moiety can be formulated as $\alpha$-L-rhamnopyranosyl- $(1 \rightarrow 4)-O-\beta$-Dglucopyranosyl- $(1 \rightarrow 6)-\beta$-D-glucopyranoside. Furthermore, as shown in Fig. 2, five signals due to terminal $\alpha$-rhamnopy- 


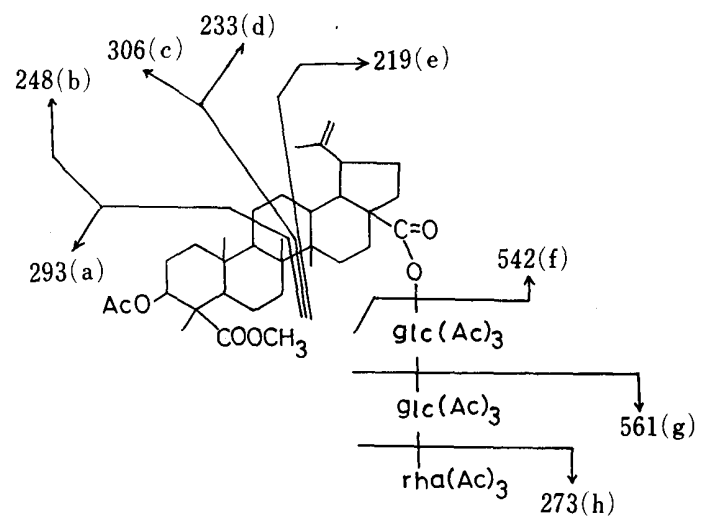

Fig. 1. EI-MS Fragmentation of 4

Table I. The ${ }^{13} \mathrm{C}-\mathrm{NMR}$ Chemical Shifts of $1(67.5 \mathrm{MHz}), 2,2 \mathrm{a}, 2 \mathbf{b}, 2 \mathrm{c}$ and 4 (each $25 \mathrm{MHz})^{a)}$ [ $\delta$ ppm from Internal TMS]

\begin{tabular}{|c|c|c|c|c|c|c|}
\hline & 1 & 2 & $2 \mathbf{a}$ & $2 c$ & $\mathbf{2 b}$ & 4 \\
\hline C. 3 & 72.7 & 72.9 & 72.5 & 210.9 & 75.2 & 75.2 \\
\hline$C-4$ & 51.6 & 52.0 & 51.6 & 61.3 & 51.5 & 51.6 \\
\hline C-5 & 46.0 & 45.0 & 45.1 & 52.4 & 45.2 & 45.2 \\
\hline C -23 & 175.1 & 179.5 & 177.9 & 173.7 & 175.3 & 175.3 \\
\hline$-\mathrm{COOCH}_{3}$ & - & - & 51.8 & 51.3 & 50.3 & 50.3 \\
\hline$C-24$ & 18.1 & 17.9 & 16.8 & 16.6 & 16.8 & 16.8 \\
\hline C-16 & 32.3 & 32.8 & 32.1 & 32.0 & 32.2 & 31.7 \\
\hline C-17 & 57.0 & 56.6 & 56.5 & 56.5 & 56.5 & 56.8 \\
\hline C-22 & 37.0 & 37.5 & 36.9 & 36.8 & 36.8 & 36.9 \\
\hline C-28 & $186.8^{b)}$ & 178.7 & 176.5 & 176.5 & 176.5 & $186.5^{b)}$ \\
\hline$-\mathrm{COOCH}_{3}$ & - & - & 51.2 & 51.2 & 51.2 & - \\
\hline
\end{tabular}

a) Solvent: $\mathrm{C}_{5} \mathrm{D}_{5} \mathrm{~N}-\mathrm{D}_{2} \mathrm{O}(2: 1)$ for $1, \mathrm{C}_{5} \mathrm{D}_{5} \mathrm{~N}$ for $2, \mathrm{CDCl}_{3}$ for $2 \mathbf{a}, \mathbf{2 b}, \mathbf{2 c}$ and 4. b) The signal was broad.

ranoside, six signals due to 4 - $\alpha$-rhamnosyl $\beta$-glucopyranoside and six signals due to 6 - $\beta$-glucosyl $\beta$-glucopyranoside were distinguishable by their respective sharpness. ${ }^{8)}$ Sugar configurations were confirmed by the ${ }^{1} \mathrm{H}-\mathrm{NMR}$ spectra of 1 and 4, which showed two anomeric protons of $\beta$-glucopyranose and one anomeric proton of $\alpha$-rhamnopyranose. Further, the ${ }^{1} J_{\mathrm{C}_{1}-\mathrm{H}}$ value of rhamnose $(168.5 \mathrm{~Hz})$ obtained from the ${ }^{13} \mathrm{C}-\mathrm{NMR}$ spectrum indicated the $\alpha$ form. ${ }^{9)}$

From these results, 1 was characterized as $3 \alpha$-hydroxylup-20(29)-ene-23,28-dioic acid 28- $O$ - $\alpha$-L-rhamnopyranosyl- $(1 \rightarrow 4)-O$ - $\beta$-D-glucopyranosyl- $(1 \rightarrow 6)-\beta$-D-glucopyranoside. As far as we know, this is the first example of the natural occurrence of a 28-oyl-glucosidated lupanetype triterpenoid.

Glycoside II (5) was isolated from the $\mathrm{MeOH}$ extract of fresh petioles, and was positive for the LiebermannBurchard reaction. Its IR spectrum showed absorption bands due to hydroxyl $\left(3400 \mathrm{~cm}^{-1}\right)$, carboxylic $\left(1680 \mathrm{~cm}^{-1}\right)$ and exo-methylene $\left(1640,875 \mathrm{~cm}^{-1}\right)$ groups and the ${ }^{1} \mathrm{H}$ NMR spectrum exhibited signals due to six tertiary methyls, two olefinic protons and one hydroxyl methine proton ( $\delta 3.66$, broad singlet).

Acid hydrolysis of 5 gave an aglycone (6) and D-glucose, but 5 was not hydrolyzed by alkali. The aglycone (6) was converted to the oxo derivative by $\mathrm{CrO}_{3}$-pyridine oxidation, and the latter was found to be identical with betulonic acid prepared by oxidation of betulinic acid. ${ }^{10}$ Then, 6 was identified as 3-epi-betulinic acid by comparison

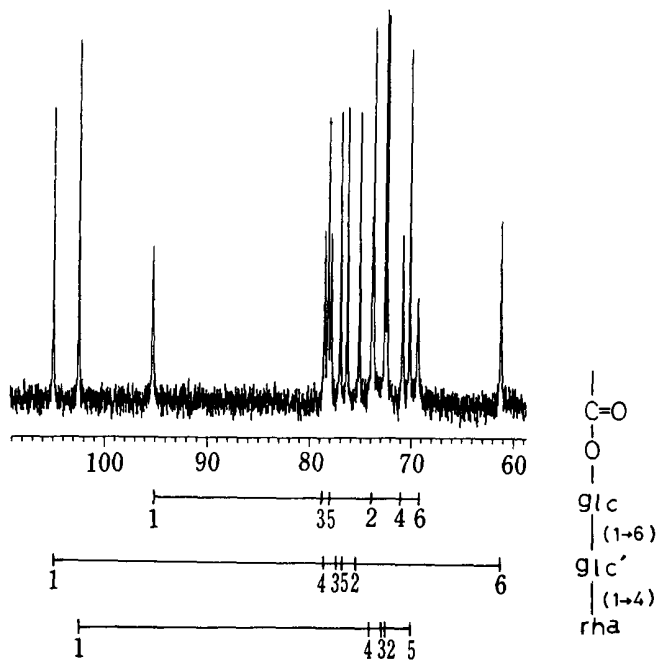

Fig. 2. Proton-Decoupled Carbon-13 Fourier-Transform NMR Spectra $(67.5 \mathrm{MHz})$ of $0.05 \mathrm{M}$ Glycoside I (1) at $60^{\circ} \mathrm{C}$

of the physical and spectral data with published values. ${ }^{11)}$ The tetraacetate (7) of 5 was obtained by the usual method, and the EI-MS of 7 exhibited peaks due to the $\mathbf{M}^{+}$ion $[\mathrm{m} / \mathrm{z}$ $\left.786\left(\mathrm{C}_{44} \mathrm{H}_{60} \mathrm{O}_{12}\right)\right]$ and the terminal tetra- $O$-acetylglucose $(\mathrm{m} / z 331,169){ }^{3)}$

The ${ }^{13} \mathrm{C}-\mathrm{NMR}$ spectrum showed a set of signals due to one molecule of $\beta$-glucopyranose, and therefore 5 was formulated as 3-epi-betulinic acid 3-O- $\beta$-D-glucopyranoside. The sugar configuration was confirmed by the ${ }^{1} \mathrm{H}-$ NMR spectrum of 7, which showed one anomeric proton of $\beta$-glucopyranose $(\delta 4.57$, doublet, $J=7 \mathrm{~Hz})$. This is the first example of the natural occurrence of 5 .

It is interesting that lupane type triterpenoid glycosides were isolated as main glycosides from an Araliaceae plant.

\section{Experimental}

Melting points were measured with a Büchi 510 melting point apparatus, and are uncorrected. IR spectra were obtained with a JASCO A103 infrared spectrophotometer. Optical rotations were determined with a JASCO DIP- 140 automatic polarimeter at $18-22^{\circ} \mathrm{C}$. EI-MS were recorded on a JEOL JMS D-300 with an accelerating potential of $7 \mathrm{kV}$, and an ionizing potential of $70 \mathrm{eV} .{ }^{1} \mathrm{H}$ - and ${ }^{13} \mathrm{C}-\mathrm{NMR}$ spectra were run on a JEOL JNM FX-100 spectrometer $\left(100 \mathrm{MHz}\right.$ for ${ }^{1} \mathrm{H}-\mathrm{NMR}, 25 \mathrm{MHz}$ for $\left.{ }^{13} \mathrm{C}-\mathrm{NMR}\right)$ and a JEOL JNM GX-270 spectrometer $\left(67.5 \mathrm{MHz}\right.$ for ${ }^{13} \mathrm{C}$ NMR): in the ${ }^{1} \mathrm{H}$ - and ${ }^{13} \mathrm{C}-\mathrm{NMR}$ studies, a 5 -mm i.d. sample tube was used. Chemical shifts were expressed as in $\delta$ values with tetramethylsilane (TMS) as an internal reference, using the solvents indicated. Thin layer chromatography (TLC) was performed on DC-Fertigplatten Kieselgel 60 (Merck) and Avicel TLC (Funakoshi). Column chromatography was carried out under TLC monitoring using Kieselgel (silica gel $0.063-$ $0.2 \mathrm{~mm}$, Merck), Silica Woelm TSC (silica gel for dry column, Woelm), a Lobar RP-8 column (Merck), Sephadex LH-20 (25-100 $\mu \mathrm{m}$, Pharmacia) and Amberlite XAD-II (Organo) in an amount equivalent to a $50-200$ fold excess over the material.

Extraction and Isolation of Glycoside I (1) and $3 \alpha$-Hydroxylup-20(29)ene-23,28-dioic Acid (2) The fresh leaf blades (0.32 kg) were extracted with $\mathrm{MeOH}(1.5 \mathrm{l})$ at room temperature. ${ }^{12)}$ After evaporation of the solvent, the syrupy residue $(19.4 \mathrm{~g})$ was extracted with $200 \mathrm{ml}$ of hot hexane (extract; $0.33 \mathrm{~g}$ ), $200 \mathrm{ml}$ of hot ether (extract; $3.43 \mathrm{~g}$ ) and $200 \mathrm{ml}$ of hot $\mathrm{MeOH}$ (extract; $11.0 \mathrm{~g}$ ) successively. The hot $\mathrm{MeOH}$-soluble fraction was subjected to column chromatography on Amberlite XAD-II $\left(\mathrm{H}_{2} \mathrm{O} \rightarrow\right.$ $\mathrm{MeOH})$. The $\mathrm{MeOH}$ eluate was repeatedly purified by column chromatography on silica gel $\left[\mathrm{CHCl}_{3}-\mathrm{MeOH}-\mathrm{H}_{2} \mathrm{O}(8: 2: 0.1 \rightarrow 7: 3: 0.5 \rightarrow 6: 4: 1)\right]$, Sephadex LH-20 (MeOH) and a Lobar RP-8 column $(60 \% \mathrm{MeOH})$ and finally $1(0.36 \mathrm{~g})$ was isolated. The hot ether soluble fraction was dissolved in $\mathrm{MeOH}(200 \mathrm{ml})$ and the solution was heated with charcoal $(7 \mathrm{~g})$ under reflux for $3 \mathrm{~h}$. After removal of the charcoal by filtration, the $\mathrm{MeOH}$ 


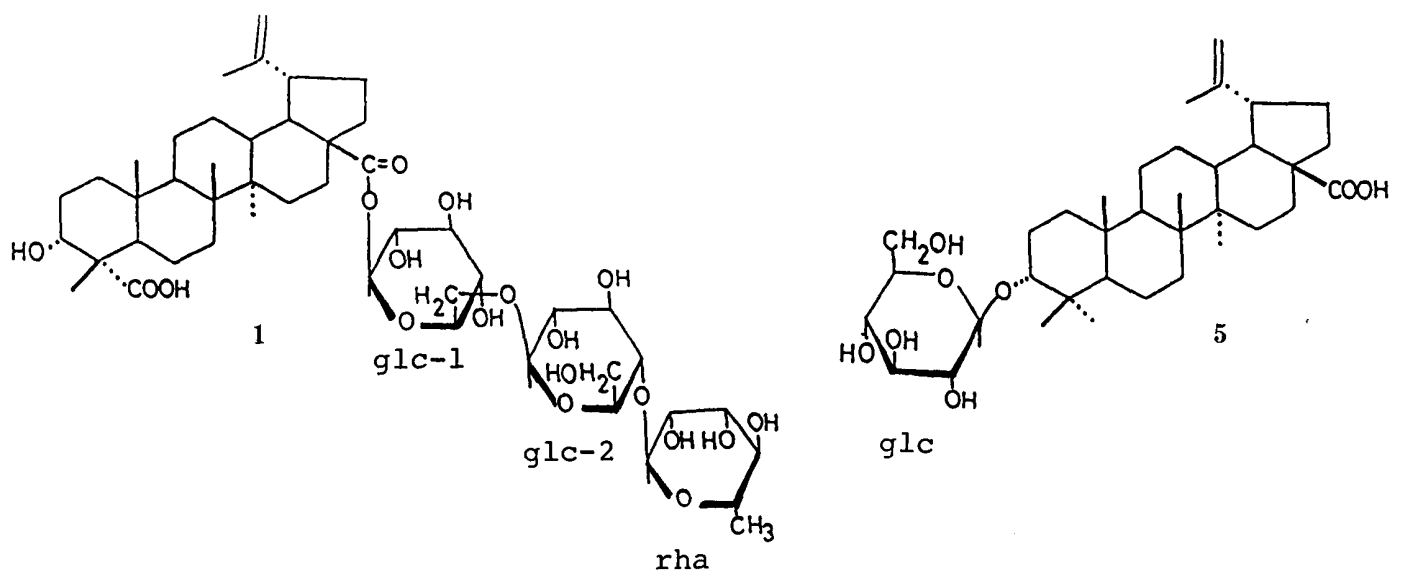

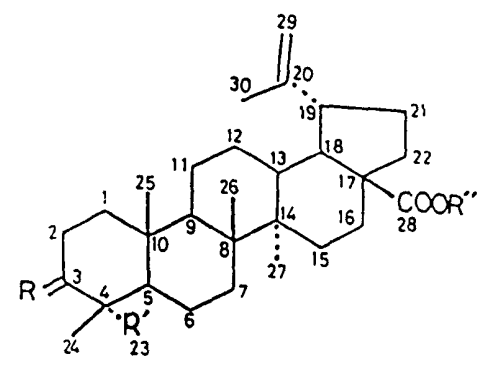

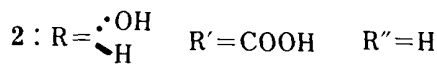

$$
\begin{aligned}
& \text { 2a : } \mathrm{R}=\dot{:}_{\mathrm{H}}^{\cdot \mathrm{OH}} \quad \mathrm{R}^{\prime}=\mathrm{COOCH}_{3} \quad \mathrm{R}^{\prime \prime}=\mathrm{CH}_{3} \\
& \text { 2b : } \mathrm{R}=\stackrel{\bullet}{:} \stackrel{\mathrm{OAc}}{\mathrm{H}}^{\prime} \quad \mathrm{R}^{\prime}=\mathrm{COOCH}_{3} \quad \mathrm{R}^{\prime \prime}=\mathrm{CH}_{3} \\
& \text { 2c : R }=0 \quad \mathrm{R}^{\prime}=\mathrm{COOCH}_{3} \quad \mathrm{R}^{\prime \prime}=\mathrm{CH}_{3} \\
& 3: \mathrm{R}=\stackrel{\bullet_{\mathrm{H}}^{\circ} \mathrm{OAc}}{\mathrm{O}} \quad \mathrm{R}^{\prime}=\mathrm{COOH} \\
& \mathrm{R}^{\prime \prime}=\operatorname{glc}(\mathrm{Ac})_{3} \stackrel{1 \rightarrow 6}{=} \operatorname{glc}(\mathrm{Ac})_{3} \stackrel{1 \rightarrow 4}{=} \mathrm{rha}(\mathrm{Ac})_{3} \\
& 4: \mathrm{R}=\stackrel{\bullet}{:} \stackrel{\mathrm{OAc}}{\mathrm{H}}_{\mathrm{R}} \mathrm{R}^{\prime}=\mathrm{COOCH}_{3}
\end{aligned}
$$

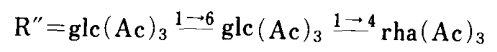

$$
\begin{aligned}
& \text { 6: } \mathrm{R}=:_{\mathrm{H}}^{\circ \mathrm{OH}} \quad \mathrm{R}^{\prime}=\mathrm{CH}_{3} \quad \mathrm{R}^{\prime \prime}=\mathrm{H}
\end{aligned}
$$

Chart 1

solution was concentrated to give a residue $(2.75 \mathrm{~g})$, which was repeatedly recrystallized from $\mathrm{MeOH}-\mathrm{H}_{2} \mathrm{O}$ and EtOAc-hexane to obtain $3 \alpha-$ hydroxylup-20(29)-ene-23,28-dioic acid $\left(2 ; 0.85 \mathrm{~g}, \mathrm{mp} 274-277^{\circ} \mathrm{C}\right)$.

Glycoside I (1) White powder, mp $274-277^{\circ} \mathrm{C}(\mathrm{dec}),[\alpha]_{\mathrm{D}}^{18}-40^{\circ}(c=$ 1.0, MeOH). Anal. Calcd for $\mathrm{C}_{48} \mathrm{H}_{76} \mathrm{O}_{19} \cdot 5 \mathrm{H}_{2} \mathrm{O}: \mathrm{C}, 55.05 ; \mathrm{H}, 8.28$. Found: C, 54.68; H, 8.17. IR $v_{\max }^{\text {Nujol }} \mathrm{cm}^{-1}: 3400(\mathrm{OH}), 1720(\mathrm{C}=\mathrm{O}), 1705(\mathrm{C}=\mathrm{O})$, $1640,880\left(\mathrm{C}=\mathrm{CH}_{2}\right) .{ }^{1} \mathrm{H}-\mathrm{NMR}\left[\mathrm{C}_{5} \mathrm{D}_{5} \mathrm{~N}-\mathrm{D}_{2} \mathrm{O}(2: 1)\right] \delta: 0.88,0.93,1.10$, $1.29,1.74\left(\right.$ each $3 \mathrm{H}, \mathrm{s}$, tert $\left.-\mathrm{CH}_{3}\right), 1.55\left(3 \mathrm{H}, \mathrm{d}, J=6 \mathrm{~Hz}\right.$, rhamnosyl $\left.\mathrm{CH}_{3}\right)$, 4.46, 4.71 (each $\left.1 \mathrm{H}, \mathrm{m}, \mathrm{C}=\mathrm{CH}_{2}\right), 4.81(1 \mathrm{H}, \mathrm{d}, J=8 \mathrm{~Hz}$, glucosyl-2 $\mathrm{H}-1$ ), $5.55(1 \mathrm{H}, \mathrm{s}$, rhamnosyl $\mathrm{H}-1), 6.12(1 \mathrm{H}, \mathrm{d}, J=7 \mathrm{~Hz}$, glucosyl-1 $\mathrm{H}-1) .{ }^{13} \mathrm{C}-$ NMR [67.5 MHz, $\left.\mathrm{C}_{5} \mathrm{D}_{5} \mathrm{~N}-\mathrm{D}_{2} \mathrm{O}(2: 1)\right] \delta: 15.2(\mathrm{C}-27), 16.5,17.0(\mathrm{C}-26, \mathrm{C}-$ 27), 18.1 (C-24), 19.5 (C-30), 20.9 (C-11), 21.6 (C-6), 26.2, 26.3 (C-2, C-12), 30.1 (C-21), 30.9 (C-15), 32.3 (C-16), 33.6 (C-1), 34.3 (C-7), 37.0 (C-22), 37.2 (C-10), 38.4 (C-13), 41.7 (C-8), 42.9 (C-14), 46.0 (C-5), 47.4 (C-18), 49.8 (C-19), 50.8 (C-9), 51.6 (C-4), 57.0 (C-17), 72.7 (C-3), 110.2 (C-29), 151.0 (C-20), 175.1 (C-23), 186.8 (C-28), glucosyl-1 [95.3 (C-1), 78.6 (C-3), 78.0 (C-5), 74.0 (C-2), 70.9 (C-4), 69.5 (C-6)], glucosyl-2 [105.0 (C-1), 78.3 (C-4), 77.0 (C-3), 76.5 (C-5), 75.3 (C-2), 61.3 (C-6)], rhamnosyl [102.6 (C1), 73.9 (C-4), 72.7, 72.5 (C-3, C-2), 70.3 (C-5), 18.2 (C-6)].

Acid Hydrolysis of $11(100 \mathrm{mg})$ was dissolved in $2 \mathrm{~N} \mathrm{H}_{2} \mathrm{SO}_{4}(10 \mathrm{ml})$ and the solution was heated on a water bath for $3 \mathrm{~h}$. The reaction mixture was diluted with water, and extracted with EtOAc. The EtOAc solution was washed with water, dried $\left(\mathrm{Na}_{2} \mathrm{SO}_{4}\right)$ and concentrated to give a residue, which was chromatographed on silica gel [hexane-EtOAc $(3: 2)$ ] to afford $2(31 \mathrm{mg})$ as needles from hexane-EtOAc; mp $274-277^{\circ} \mathrm{C},[\alpha]_{\mathrm{D}}^{18}-11^{\circ}$ ( $c=1.0, \mathrm{MeOH}$ ), $\mathrm{C}_{30} \mathrm{H}_{46} \mathrm{O}_{5}$ (Obsd, 486.3345; Calcd, 486.3345). EI-MS $m / z: 486\left(\mathrm{M}^{+}\right), 468,440,424,259,250$ (c), 248 (b), 234 (d), 219 (e), 203, 189 (base), 175, 173, 121. IR $v_{\max }^{\mathrm{Nujol}} \mathrm{cm}^{-1}: 3300(\mathrm{OH}), 1700(\mathrm{C}=\mathrm{O}), 1640,890$ $\left(\mathrm{C}=\mathrm{CH}_{2}\right) .{ }^{1} \mathrm{H}-\mathrm{NMR}\left[\mathrm{CDCl}_{3}-\mathrm{CD}_{3} \mathrm{OD}(3: 1)\right] \delta: 0.88,0.96,1.02,1.16,1.69$ (each $3 \mathrm{H}, \mathrm{s}$, tert $\left.-\mathrm{CH}_{3}\right), 3.76(1 \mathrm{H}$, br s, $3 \beta-\mathrm{H}), 4.58,4.71($ each $1 \mathrm{H}, \mathrm{C}=$ $\mathrm{CH}_{2}$ ). The compound was identical with authentic $3 \alpha$-hydroxylup-20(29)ene-23,28-dioic acid, which was obtained from the hot ether extract of this material (IR, mp).
The aqueous layer of the hydrolysate was neutralized with $\mathrm{NaHCO}_{3}$ and evaporated. The residue was treated with $\mathrm{MeOH}$, then filtered, and the filtrate passed through Sephadex $\mathrm{LH}-20(\mathrm{MeOH})$. The sugar fraction was chromatographed on silica gel $\left[\mathrm{CHCl}_{3}-\mathrm{MeOH}-\mathrm{H}_{2} \mathrm{O}(7: 3: 0.5)\right]$ to give two sugars. Sugar 1: Syrup, $[\alpha]_{\mathrm{D}}^{20}+54^{\circ}(c=0.7, \mathrm{MeOH})$. Avicel TLC $(R f$ 0.25 , solv. A). ${ }^{13)}$ Sugar 2 : Syrup, $[\alpha]_{\mathrm{D}}^{20}+10^{\circ}(c=0.5, \mathrm{MeOH})$. Avicel TLC $\left(\right.$ Rf 0.50 , solv. A) ${ }^{13)}$ These were identified as D-glucose and L-rhamnose, respectively.

Partial Hydrolysis of 1 with $0.3 \mathrm{~N} \mathrm{H}_{2} \mathrm{SO}_{4} \quad 1(100 \mathrm{mg})$ was dissolved in $0.3 \mathrm{~N} \mathrm{H}_{2} \mathrm{SO}_{4}-\mathrm{MeOH}(10 \mathrm{ml})$ and the solution was heated under reflux for $2 \mathrm{~h}$. The reaction mixture was neutralized with $\mathrm{Na}_{2} \mathrm{CO}_{3}$, the salt was filtered off, and the filtrate was passed through Sephadex LH-20 (MeOH). The eluate was evaporated and the residue was chromatographed on silica gel $\left[\mathrm{CHCl}_{3}-\mathrm{MeOH}-\mathrm{H}_{2} \mathrm{O}(9: 1: 0.05 \rightarrow 8: 2: 0.2 \rightarrow 7: 3: 0.5)\right]$ to give a methyl disaccharide together with methyl glucoside, methyl rhamnoside and 2. This disaccharide was identified as methyl gentiobioside (a mixture of the $\alpha$ and $\beta$ forms from the ${ }^{13} \mathrm{C}-\mathrm{NMR}$ spectral data; $\left.25 \mathrm{MHz}, \mathrm{C}_{5} \mathrm{D}_{5} \mathrm{~N}\right) \delta$ : methyl glucosyl-1 [105.6 ( $\beta$-C-1), $101.4(\alpha-\mathrm{C}-1), 78.5(\beta$-C-3), $77.2(\beta-\mathrm{C}-5)$, $75.4(\alpha-\mathrm{C}-3), 74.9(\beta-\mathrm{C}-2), 73.7(\alpha-\mathrm{C}-2), 72.9(\alpha-\mathrm{C}-5), 71.9(\alpha-\mathrm{C}-4), 71.5(\beta-$ $\left.\mathrm{C}-4), 70.0(\mathrm{C}-6), 56.8\left(\beta-\mathrm{OCH}_{3}\right), 55.2\left(\alpha-\mathrm{OCH}_{3}\right)\right]$, glucosyl-2 [105.4 (C-1), 78.5 (C-3, C-5), 75.2 (C-2), 71.6 (C-4), 62.7 (C-6)].

Alkaline Hydrolysis of $1 \quad 1(30 \mathrm{mg})$ was dissolved in $1 \% \mathrm{NaOH}-50 \%$ $\mathrm{MeOH}(5 \mathrm{ml})$ and the solution was heated on a water bath for $3 \mathrm{~h}$. The reaction mixture was diluted with water and neutralized with $1 \mathrm{~N} \mathrm{HCl}$, then extracted with EtOAc. From the EtOAc solution, $2(11 \mathrm{mg})$ was obtained in the same way.

Acetylation and Methylation of $1 \quad 1(40 \mathrm{mg})$ was acetylated with $\mathrm{Ac}_{2} \mathrm{O}$ and pyridine at room temperature for $12 \mathrm{~h}$, to give a peracetate of $1(3$; $42 \mathrm{mg}$ ) as colorless needles from $\mathrm{MeOH} ; \mathrm{mp} 168-170^{\circ} \mathrm{C}$. EI-MS $\mathrm{m} / z: 561$ (g), 501, 424, 409, 379, 317, 273 (h), 248 (b), 231, 219 (e), 213, 201, 189, 173, 153 (base).

$3(35 \mathrm{mg})$ was dissolved in ether and the solution was treated with ethereal diazomethane. The product was recrystallized from $\mathrm{MeOH}$ and 
the 23-monomethylate of $3(4 ; 32 \mathrm{mg})$ was obtained as colorless needles, $\mathrm{mp}$ 175-178 C. EI-MS m/z: 561 (g), 542 (f), 496, 436, 422, 306 (c), 293 (a), 273 (h), 248 (b, base), 234, 233 (d), 219 (e), 203, 189. ${ }^{1} \mathrm{H}-\mathrm{NMR}\left(\mathrm{CDCl}_{3}\right) \delta$ : $0.90,0.93,1.05,1.21,1.68\left(\right.$ each $3 \mathrm{H}, \mathrm{s}$, tert $\left.-\mathrm{CH}_{3}\right), 1.18(3 \mathrm{H}, \mathrm{d}, J=5 \mathrm{~Hz}$, rhamnosyl $\left.\mathrm{CH}_{3}\right), 1.99-2.12(30 \mathrm{H}, \mathrm{OAc}), 3.58\left(3 \mathrm{H}, \mathrm{s}, \mathrm{COOCH}_{3}\right), 4.60$, $4.75\left(\right.$ each $\left.2 \mathrm{H}, \mathrm{m}, \mathrm{C}=\mathrm{CH}_{2}\right), 4.51(1 \mathrm{H}, \mathrm{d}, J=7 \mathrm{~Hz}$, glucosyl-2 $\mathrm{H}-1), 5.02$ $(1 \mathrm{H}$, br s, rhamnosyl $\mathrm{H}-1), 5.67(1 \mathrm{H}, \mathrm{d}, J=7 \mathrm{~Hz}$, glucosyl-1 $\mathrm{H}-1),{ }^{13} \mathrm{C}-$ NMR $\left(25 \mathrm{MHz}, \mathrm{CDCl}_{3}\right) \delta$ : Table I.

23,28-Dimethylate of 2 (2a) 2a was obtained from 2 by treatment with ethereal diazomethane in $\mathrm{MeOH}$; amorphous. EI-MS $m / z: 514\left(\mathrm{M}^{+}\right.$, $\mathrm{C}_{32} \mathrm{H}_{50} \mathrm{O}_{5}$ ), 496, 482, 454, 264 (c), 262 (b), 251 (a), 249 (d-H), 248, 233 (e), 203, 189 (base), 175. ${ }^{1} \mathrm{H}-\mathrm{NMR}\left(\mathrm{CDCl}_{3}\right) \delta: 0.87,0.92,1.00,1.16,1.69$ (each $3 \mathrm{H}, \mathrm{s}$, tert $\left.-\mathrm{CH}_{3}\right), 3.60,3.70\left(\right.$ each $\left.3 \mathrm{H}, \mathrm{s}, \mathrm{COOCH}{ }_{3}\right), 3.70(1 \mathrm{H}$, br s, $3 \beta-\mathrm{H})$, 4.60, $4.73\left(\right.$ each $\left.1 \mathrm{H}, \mathrm{m}, \mathrm{C}=\mathrm{CH}_{2}\right) \cdot{ }^{13} \mathrm{C}$-NMR $\left(25 \mathrm{MHz}, \mathrm{CDCl}_{3}\right)$ : Table I.

3-Acetyl-23,28-dimethylate of 2 (2b) 2 b was obtained from 2 a by treatment with $\mathrm{Ac}_{2} \mathrm{O}$ and pyridine at room temperature; amorphous. EIMS $m / z$ : $556\left(\mathrm{M}^{+}, \mathrm{C}_{34} \mathrm{H}_{52} \mathrm{O}_{6}\right), 496,437,421,306$ (c), 293 (a), 262 (b), 248 (d), 233 (e), 203, 189 (base). ' $\mathrm{H}-\mathrm{NMR}\left(\mathrm{CDCl}_{3}\right) \delta: 0.88,0.94,1.05,1.21$, 1.69 (each $3 \mathrm{H}, \mathrm{s}$, tert $-\mathrm{CH}_{3}$ ), $2.01(3 \mathrm{H}, \mathrm{s}, \mathrm{OAc}$ ), 3.58, 3.67 (each $3 \mathrm{H}, \mathrm{s}$, $\left.\mathrm{COOCH}_{3}\right), 4.59,4.73\left(\right.$ each $\left.1 \mathrm{H}, \mathrm{m}, \mathrm{C}=\mathrm{CH}_{2}\right), 4.93(1 \mathrm{H}$, br s, $3 \beta-\mathrm{H}) .{ }^{13} \mathrm{C}-$ NMR $\left(25 \mathrm{MHz}, \mathrm{CDCl}_{3}\right)$ : Table I.

3-Oxo-23,28-dimethylate of 2 (2c) 2c was obtained from 2a by treatment with chromic oxide and pyridine (in the same way as described for the $\mathrm{CrO}_{3}$ oxidation of 6 ), and recovered as needles from hexane; $\mathrm{mp} 132$ $134 \mathrm{C} .{ }^{1} \mathrm{H}-\mathrm{NMR}\left(\mathrm{CDCl}_{3}\right) \delta: 0.95,0.99,0.99,1.33,1.69$ (each $3 \mathrm{H}, \mathrm{s}$, tert$\left.\mathrm{CH}_{3}\right), 3.67,3.71\left(\right.$ each $\left.3 \mathrm{H}, \mathrm{s}, \mathrm{COOCH}_{3}\right), 4.61,4.73\left(\right.$ each $\left.1 \mathrm{H}, \mathrm{m}, \mathrm{C}=\mathrm{CH}_{2}\right)$. ${ }^{13} \mathrm{C}$-NMR (25 MHz, $\mathrm{CDCl}_{3}$ ): Table I.

Extraction and Isolation of Glycoside II (5) The fresh petioles $(0.12 \mathrm{~kg})$ were extracted with $\mathrm{MeOH}(1.01)$ at room temperature. ${ }^{12)}$ After evaporation of the solvent, the syrupy residue $(9.6 \mathrm{~g})$ was extracted with $200 \mathrm{ml}$ of hot acetone (extract; $1.87 \mathrm{~g}$ ) and $200 \mathrm{ml}$ of hot $\mathrm{MeOH}$ (extract; $6.7 \mathrm{~g}$ ) successively. The hot acetone soluble fraction was subjected to column chromatography on silica gel $\left[\mathrm{CHCl}_{3}-\mathrm{MeOH}-\mathrm{H}_{2} \mathrm{O}(9: \mathrm{I}: 0.05 \rightarrow 8: 2: 0.2)\right]$ to give a fraction containing 2 and glycoside $\mathrm{II}(5)$. This fraction was repeatedly fractionated by column chromatography on silica gel $\left[\mathrm{CHCl}_{3}-\right.$ MeOH- $\left.\mathrm{H}_{2} \mathrm{O}(9: 1: 0.05)\right]$ and Sephadex LH-20 (MeOH), and $5(0.06 \mathrm{~g})$ was isolated.

Glycoside II (5) White powder, mp $265-267^{\circ} \mathrm{C}(\mathrm{dec}),[\alpha]_{\mathrm{D}}^{22}-9^{\circ}(c=$ 1.0 , pyridine). IR $v_{\max }^{\mathrm{Nujol}} \mathrm{cm}^{-1}: 3400(\mathrm{OH}), 1680(\mathrm{C}=\mathrm{O}), 1640,875(\mathrm{C}=$ $\left.\mathrm{CH}_{2}\right) .{ }^{1} \mathrm{H}-\mathrm{NMR}\left(\mathrm{C}_{5} \mathrm{D}_{5} \mathrm{~N}\right) \delta: 0.78,0.82,0.82,1.03,1.24,1.78($ each $3 \mathrm{H}, \mathrm{s}$, tert $\left.-\mathrm{CH}_{3}\right), 3.66(1 \mathrm{H}$, br s, $3 \beta-\mathrm{H}), 4.81,4.90\left(\right.$ each $\left.1 \mathrm{H}, \mathrm{m}, \mathrm{C}=\mathrm{CH}_{2}\right) .{ }^{13} \mathrm{C}$ NMR $\left(25 \mathrm{MHz}, \mathrm{C}_{5} \mathrm{D}_{5} \mathrm{~N}\right) \delta: 14.9(\mathrm{C}-27), 16.3(\mathrm{C}-25, \mathrm{C}-26), 18.5(\mathrm{C}-6), 19.5$ (C-30), 21.0 (C-11), 21.7 (C-2), 22.6 (C-24), 26.0 (C-12), 29.3 (C-23), 30.2 (C-21), 31.1 (C-15), 32.7 (C-16), 33.9 (C-1), 34.5 (C-7), 37.5 (C-4, C-10, C 22), 38.5 (C-13), 41.2 (C-8), 42.7 (C-14), 47.7 (C-18), 49.7 (C-19), 50.3 (C-5, C-9), 56.5 (C-17), 82.0 (C-3), 109.8 (C-29), 151.2 (C-20), 178.7 (C-28), glucosyl [102.2 (C-1), 78.7, 78.2 (C-3, C-5), 74.9 (C-2), 72.0 (C-4), 63.1 (C6)]. ${ }^{14)}$

Acid Hydrolysis of $5 \mathbf{5}(30 \mathrm{mg})$ was dissolved in $2 \mathrm{~N} \mathrm{H}_{2} \mathrm{SO}_{4}(5 \mathrm{ml})$ and the solution was heated on a water bath for $3 \mathrm{~h}$. The reaction mixture was diluted with water and extracted with ether. The ethereal solution was washed with water, dried $\left(\mathrm{Na}_{2} \mathrm{SO}_{4}\right)$ and concentrated to give a residue, which was then chromatographed on silica gel [hexane-EtOAc $(7: 3)$ ] to afford $6(12 \mathrm{mg})$, obtained as needles from hexane-EtOAc; mp 278$282^{\circ} \mathrm{C},[\alpha]_{\mathrm{D}}^{20}-13^{\circ}\left(c=0.5, \mathrm{CHCl}_{3}\right)$. EI-MS $m / z: 456\left(\mathrm{M}^{+}, \mathrm{C}_{30} \mathrm{H}_{48} \mathrm{O}_{3}\right), 438$, 423, 248, 220, 219, 207, 189 (base), 167. IR $v_{\max }^{\mathrm{Nujol}} \mathrm{cm}^{-1}: 3400(\mathrm{OH}), 1700$ $(\mathrm{C}=\mathrm{O}), 1640,890\left(\mathrm{C}=\mathrm{CH}_{2}\right) .{ }^{1} \mathrm{H}-\mathrm{NMR}\left[\mathrm{CDCl}_{3}-\mathrm{C}_{5} \mathrm{D}_{5} \mathrm{~N}(4: 1)\right] \delta: 0.82$, $0.83,0.98,0.98,0.98,1.71\left(\right.$ each $3 \mathrm{H}, \mathrm{s}$, tert $\left.-\mathrm{CH}_{3}\right), 3.41(1 \mathrm{H}, \mathrm{m}, 3 \beta-\mathrm{H}), 4.62$, 4.77 (each $1 \mathrm{H}, \mathrm{m}, \mathrm{C}=\mathrm{CH}_{2}$ ).

The aqueous layer of the hydrolysate was neutralized with $\mathrm{NaHCO}_{3}$, and evaporated. The residue was treated with $\mathrm{MeOH}$, then filtered, and the filtrate was passed through Sephadex $\mathrm{LH}-20(\mathrm{MeOH})$. The sugar fraction was chromatographed on silica gel $\left[\mathrm{CHCl}_{3}-\mathrm{MeOH}-\mathrm{H}_{2} \mathrm{O}(7: 3: 0.5)\right]$ to give a syrup, and Avicel TLC $\left(R f 0.50\right.$, solv. A), ${ }^{13)}$ showed the presence of D-glucose.
$\mathrm{CrO}_{3}$-Oxidation of 6 A solution of $6(10 \mathrm{mg})$ in pyridine was added to a stirred solution of chromic oxide $(30 \mathrm{mg})$ in pyridine $(3 \mathrm{ml})$. The mixture was stirred for $12 \mathrm{~h}$ at room temperature, then diluted with water and extracted with ether. The ether solution was washed with water, dried $\left(\mathrm{Na}_{2} \mathrm{SO}_{4}\right)$ and then evaporated. The residue was purified by chromatography on silica gel [hexane-EtOAc $(4: 1)$ ] to give betulonic acid $(5 \mathrm{mg})$, obtained as needles from $\mathrm{MeOH}, \mathrm{mp} 256-258^{\circ} \mathrm{C} .{ }^{1} \mathrm{H}-\mathrm{NMR}\left(\mathrm{CDCl}_{3}\right) \delta$ : $0.93,0.98,0.99,1.02,1.07,1.70\left(\right.$ each $3 \mathrm{H}, \mathrm{s}$, tert $\left.-\mathrm{CH}_{3}\right), 4.62,4.73($ each $1 \mathrm{H}$, $\left.\mathrm{m}, \mathrm{C}=\mathrm{CH}_{2}\right)$. The compound was identical with a sample $\left({ }^{1} \mathrm{H}-\mathrm{NMR}, \mathrm{mp}\right)$ prepared from betulinic acid in the same way.

Alkaline Hydrolysis of $5 \mathbf{5}(15 \mathrm{mg})$ was dissolved in $1 \% \mathrm{NaOH}-50 \%$ $\mathrm{MeOH}(3 \mathrm{ml})$ and the solution was treated in the same way as described for the alkaline hydrolysis of 1. From the EtOAc extract residue, only the starting material was obtained.

Acetylation of $55(15 \mathrm{mg})$ was acetylated with $\mathrm{Ac}_{2} \mathrm{O}$ and pyridine at room temperature for $12 \mathrm{~h}$ and the product was purified by column chromatography on silica gel [hexane-EtOAc (7:3)]. Recrystallization from $\mathrm{MeOH}$ afforded a tetraacetate of $5(7)$ as colorless needles, $\mathrm{mp} 289$ $290 \mathrm{C}$ (dec.), $\mathrm{C}_{44} \mathrm{H}_{66} \mathrm{O}_{12}$ (Obsd, 786.4608; Calcd, 786.4661). EI-MS m/z: $786\left(\mathrm{M}^{+}\right), 740,438$ (base), 423, 331, 203, 189, 169. ${ }^{1} \mathrm{H}-\mathrm{NMR}\left(\mathrm{CDCl}_{3}\right) \delta$ : $0.82,0.82,0.91,0.91,0.98,1.68$ (each $3 \mathrm{H}, \mathrm{s}$, tert $\left.-\mathrm{CH}_{3}\right), 2.01,2.03,2.04$, 2.07 (each $3 \mathrm{H}, \mathrm{s}, \mathrm{OAc}), 4.57(1 \mathrm{H}, \mathrm{d}, J=7 \mathrm{~Hz}$, glucosyl $\mathrm{H}-1), 4.60,4.72$ (each $1 \mathrm{H}, \mathrm{m}, \mathrm{C}=\mathrm{CH}_{2}$ ).

Acknowledgements The authors are grateful to Prof. T. Komori of Kyushu University for valuable discussions. Thanks are also extended to Mr. Y. Takase of the Central Analytical Department of this college for MS and ${ }^{13} \mathrm{C}-\mathrm{NMR}(67.5 \mathrm{MHz})$ measurements.

\section{References and Notes}

1) G. Adam, M. Lischewski, H. V. Phiet, A. Preiss, J. Shmidt and T. V. Sung, Phytochemistry, 21, 1385 (1982).

2) M. Lischewski, P. D. Ty, J. Schmidt, A. Preiss, H. V. Pheit and G. Adam, Phytochemistry, 23, 1695 (1984).

3) T. Komori, Y. Ida, Y. Muto, K. Miyahara, T. Nohara and T. Kawasaki, Biomed. Mass Spectometry, 2, 65 (1975).

4) S. Yahara, R. Kasai and O. Tanaka, Chem. Pharm. Bull., 25, 2041 (1977).

5) A set of PRFT spectra was measured with the pulse intervals (s) of $0.09,0.12$ and 0.14 with a recycle time of $3.6 \mathrm{~s}$.

6) a) J. Kitajima, T. Komori, T. Kawasaki and H. R. Shulten, Phytochemistry, 21, 187 (1982); b) S. B. Mahato, N. P. Sahu, A. N. Ganguly, R. Kasai and O. Tanaka, ibid., 19, 2017 (1980); c) S. Seo, Y. Tomita, K. Tori and Y. Yoshimura, J. Am. Chem. Soc., 100, 3331 (1978).

7) M. Takai, S. Amagaya and Y. Ogihara, J. Chem. Soc., Perkin Trans. 1, 1977, 1801.

8) K. Tori, Y. Takeguchi and K. Yoshikawa, "Jituyo NMR," Kodansha, Tokyo, 1984, p. 149

9) M. Okihara, R. Kasai and O. Tanaka, Abstracts of Papers, 98th Annual Meeting of the Pharmaceutical Society of Japan, Okayama, April 1978, p. 307.

10) A. G. Gonzalez, J. Amaro, B. M. Fraga and J. G. Luis, Phytochemistry, 22, 1823 (1983).

11) W. Herz, P. S. Santhanam and I. Wahlberg, Phytochemistry, 11, 3061 (1972).

12) The material was collected at Amami Oshima (Kagoshima prefecture) in Feburary, 1987.

13) Solv. A: upper layer of $n-\mathrm{BuOH}$-pyridine- $\mathrm{H}_{2} \mathrm{O}(6: 2: 3)+$ an equal volume of pyridine.

14) With regard to carbon signals of the aglycone, see $M$. Sholichin, $K$. Yamasaki, R. Kasai and O. Tanaka, Chem. Pharm. Bull., 28, 1006 (1980). 